\title{
AN UNUSUAL LARGE CENTRAL (INTRAOSSEOUS) CALCIFYING EPITHELIAL ODONTOGENIC TUMOUR (PINDBORG TUMOUR) EVALUATED BY 64-SLICE MDCT AND DIGITAL RADIOGRAPH WITH HISTOPATHOLOGICAL CORRELATION- A CASE REPORT WITH LITERATURE REVIEW
}

\author{
Dipu Singh1, Arvind Srivastava2, Ramchandra Shukla ${ }^{3}$, Amit Nandan Dhar Dwivedi', Dharmendra K. R. Bairwa $^{5}$
}

1 Junior Resident, Department of Radio-Diagnosis and Imaging, Institute of Medical Sciences, BHU, Varanasi.

2 Professor and HOD, Department of Radio-Diagnosis and Imaging, Institute of Medical Sciences, BHU, Varanasi.

${ }^{3}$ Professor, Department of Radio-Diagnosis and Imaging, Institute of Medical Sciences, BHU, Varanasi.

${ }^{4}$ Associate Professor, Department of Radio-Diagnosis and Imaging, Institute of Medical Sciences, BHU, Varanasi.

5Junior Resident, Department of Radio-Diagnosis and Imaging, Institute of Medical Sciences, BHU, Varanasi.

HOW TO CITE THIS ARTICLE: Singh D, Srivastava A, Shukla R, et al. An unusual large central (intraosseous) calcifying epithelial odontogenic tumour (Pindborg tumour) evaluated by 64-slice MDCT and digital radiograph with histopathological correlation- a case report with literature review. J. Evolution Med. Dent. Sci. 2017;6(43):3401-3403, DOI: 10.14260/Jemds/2017/737

\section{PRESENTATION OF CASE}

A 35-year-old female presented with firm, mandibular swelling localised in right hemi-mandible involving body and reaching up to symphysis menti. Clinically, patient was reported to the Dental Department complaining of an asymptomatic slow-growing swelling, which gradually increased to the present size within a period of 2 years' duration in the lower right hemi-mandibular region. The onset was spontaneous and there was no history of trauma or functional impairment. Extraoral examination and palpation revealed few cervical lymph nodes of normal size and consistency. On intraoral examination the painless, firm, swelling of $(6 \times 7 \times 8 \mathrm{~cm})$ mass was located in the right hemimandibular body covered by a normal oral mucosa. (Fig. 1) Digital left oblique radiograph (Figure A) showed a large expansile lesion with central crown involvement with dense calcification (white arrow) in right mandible involving body and reaching upto symphysis menti; while MDCT axial (Figure B), sagittal (Figure C) and 3D (Figure D) showing buccal and lingual cortical breech (Yellow arrow) and central crown of molar with dense calcified materials with subtle flakes appearance (red arrow) and $3^{\text {rd }}$ molar tooth root erosion (Blue arrow) (Figure 2).

The decision was made to excise the lesion under general anaesthesia and histopathological evaluation.

\section{DIFFERENTIAL DIAGNOSIS}

I am aware of the diagnosis in this case. This patient is middle aged female with overall excellent health with large external expansile swelling in right lower jaw region is noted. The key finding on clinical evaluation is the lesion originating and involving right hemi-mandibular body region. The findings on imaging can be explained as mixed radiolucent radiopaque lesion, so diagnosis are Central Calcifying Epithelial Odontogenic Tumour (CEOT), Calcifying odontogenic cyst, Adenomatoid odontogenic tumour, Complex odontoma, Ameloblastic fibro-odontoma, Fibro-osseous lesions and

Financial or Other, Competing Interest: None.

Submission 28-04-2017, Peer Review 19-05-2017,

Acceptance 22-05-2017, Published 29-05-2017.

Corresponding Author:

Dr. Dipu Singh,

Institute of Medical Sciences,

BHU, Varanasi-221005,

Uttar Pradesh.

E-mail: deepimsbhu@gmail.com

DOI: $10.14260 /$ jemds $/ 2017 / 737$ osteoblastoma should be considered. ${ }^{1}$ A radiopaque irregular mass was seen in the centre of the tumour, which could have been a calcified mass like a complex odontoma or the crown of an impacted tooth. When associated with an unerupted/impacted tooth, the radiopacities may be seen clustering near the tooth crown with the apex perforating the cortex, which is confused with other lesions associated with impacted tooth such as dentigerous cyst, AOT (Adenomatoid Odontogenic Tumour) and the calcifying odontogenic cyst. ${ }^{2}$ Multiplanar CT images and computer-aided three-dimensional reconstructions are helpful in delineating the extent of the lesion and making diagnosis.

\section{CLINICAL DIAGNOSIS}

Clinically, patient had an asymptomatic slow-growing huge expansile swelling in lower right hemi-mandibular region, which gradually is increasing in size with no history of trauma or functional impairment. There are also few cervical lymph nodes of normal size and consistency noted ipsilaterally. On intraoral examination the painless, firm, swelling located in the right hemi-mandibular body covered by a normal oral mucosa. After digital radiography and MDCT evaluation, we made our first consideration of intraosseous (central) calcified epithelial odontogenic tumour (CEOT).

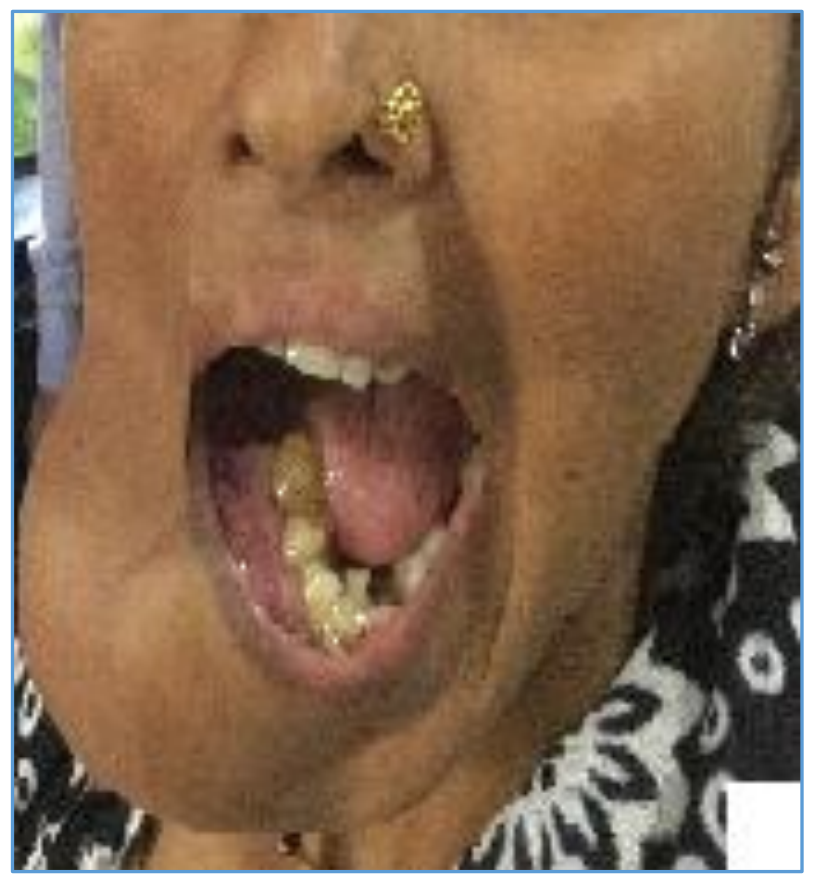

Figure 1 


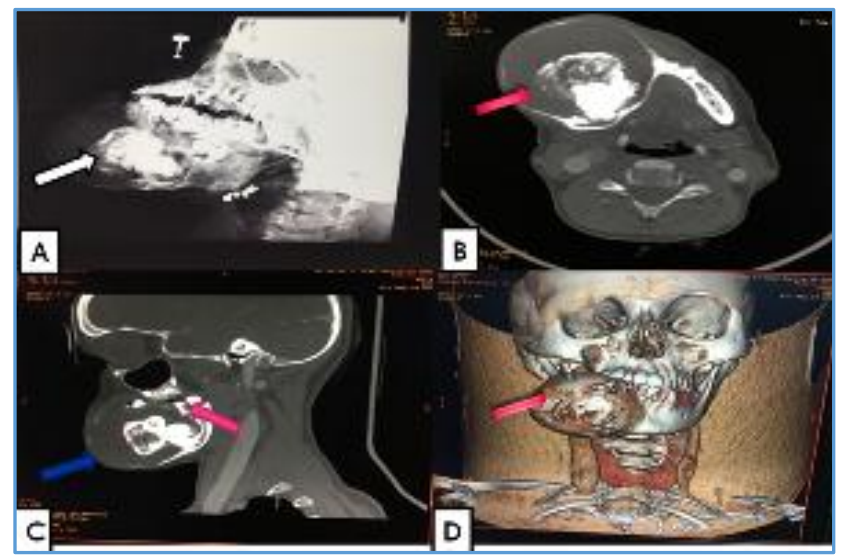

Figure 2

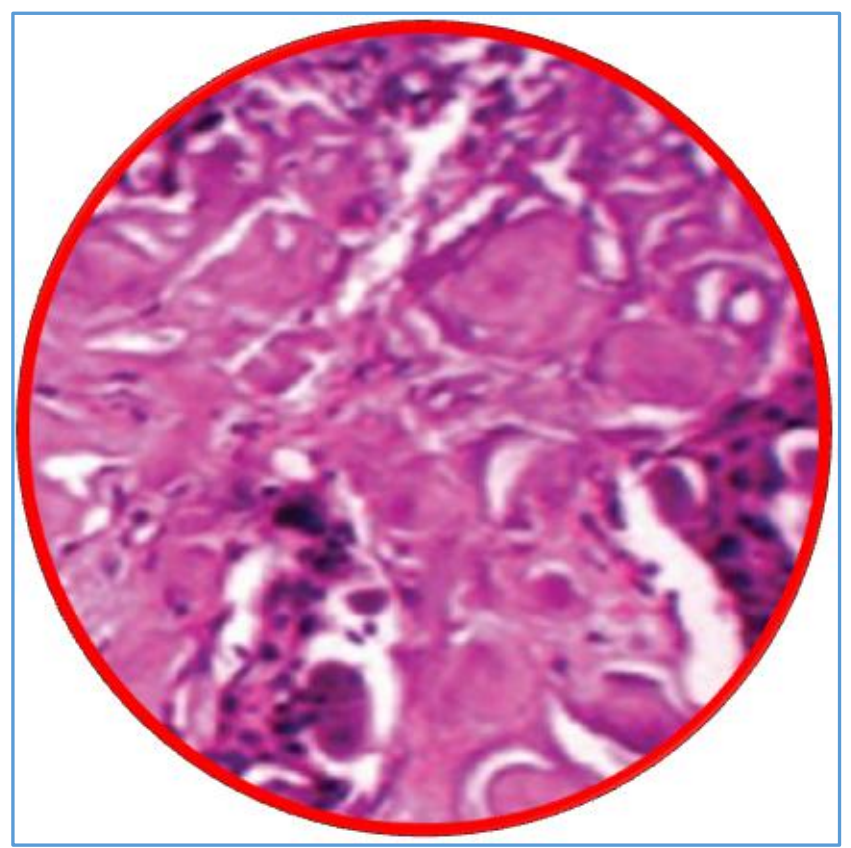

Figure 3

\section{PATHOLOGICAL DISCUSSION}

Histopathological examination (Figure 3) showed stained with eosin and haematoxylin showing concentric calcified rings, polygonal cell and intercellular bridges. A final diagnosis of central calcifying epithelial odontogenic tumour was considered. Due to the similarity of cellular pattern with various lesions, immunohistochemistry shall be performed to differentiate CEOT from other benign odontogenic tumour (esp. ameloblastoma), minor salivary gland tumour and oral squamous carcinoma. ${ }^{3}$ Histologically, small amounts of mineralised material might be observed, which is a common finding in peripheral CEOT types. Over the years, the histology of CEOTs has been well documented. Subclassified this tumour into four distinct microscopic patterns, although two or more types may be present in the same tumour. Type 1 consists of sheets, nests and masses of polyhedral epithelial cells exhibiting prominent intercellular bridges. Type 2 is characterised by a cribriform arrangement of tumour cells. Type 3 consists of scattered or densely populated tumour cells. Type 4 is characterised by small nests and cords of epithelial cells. In addition, several cellular variants such as clear cell, pigmented, Langerhans cell containing bone and cementum forming, myoepithelial cell and non-calcifying subtypes have been reported. According to the histologic classification of $\mathrm{Ai}-\mathrm{Ru}$ et $\mathrm{al}^{4}$ In the present case, type 1 histopathological findings are present.

\section{DISCUSSION OF MANAGEMENT}

Central Calcifying Epithelial Odontogenic Tumour (CEOT) is a rare benign tumour. Although CEOT is a benign neoplasm, its biologic behaviour is variable, ranging from very slight to moderately invasive. ${ }^{2}$ CEOT occur over a broad age range; however, they are slightly more common between 3rd and 6th decades of life. 5 There is no gender predilection. In present study, single case of CEOT patient aged 35 years female was noted. About half of the cases of CEOT are associated with an impacted tooth, usually with a mandibular molar tooth. ${ }^{6}$ The treatment methods can range from simple enucleation or curettage to hemi-mandibulectomy or hemimaxillectomy. ${ }^{7}$ Enucleation with a margin of normal tissue is usually recommended for mandibular lesions. CEOT of the maxilla should be treated more aggressively as maxillary tumours grow more rapidly and are usually not well confined. Treatment, however, should be individualised for each case. ${ }^{7}$ As our patient had large expansile swelling of $6 \times 7 \times 8 \mathrm{~cm}$ in the right hemi-mandibular body reaching up to symphysis menti with central crown involvement and dense calcification in showing buccal and lingual cortical breech, the decision was made to excise the lesion under general anaesthesia. The patient underwent right hemi-mandibulectomy and no recurrence is reported in 6 months of followup. Long-term followup, at least 5 years, is a must as there is high risk of recurrence if the tumour was incompletely resected, especially with clear cell variant, which is locally more aggressive. The recurrence rate may range from $14 \%$ to $20 \%$. The malignant behaviour is extremely rare. ${ }^{8}$

\section{FINAL DIAGNOSIS}

Giant Central (Intraosseous) Calcifying Epithelial Odontogenic Tumour (CEOT).

\section{REFERENCES}

[1] Wood N, Goaz P. Differential diagnosis of oral and maxillofacial lesions. $5^{\text {th }}$ edn. St. Louis: Mosby Yearbook 1997:428-31.

[2] Kim WK, Kim MS, Lee EM, et al. Calcifying epithelial odontogenic tumor associated with the left mandibular first premolar: a case report and literature review. J Korean Assoc Oral Maxillofac Surg 2012;38:166-70.

[3] Lin J, Bianchi M, Popnikolov NK, et al. Calcifying epithelial odontogenic tumor: case report with immunohistochemical and ultrastructural study and review of the literature.J Oral Maxillofac Surg 2013;71(2):278-89.

[4] Ai-Ru L, Zhen L, Jian S. Calcifying epithelial odontogenic tumors: a clinicopathologic study of nine cases. J Oral Pathol 1982;11(5):399-406.

[5] Rajendran R. Cysts and tumors of odontogenic origin. In: Sivapathasundharam B, (edr). Shafer's textbook of oral pathology. $6^{\text {th }}$ edn. New Delhi: Elsevier 2009:27881.

[6] Reichart PA, Philipsen HP, Sonner S. Ameloblastoma: biological profile of 3677 cases. Eur J Cancer B Oral Oncol 1995;31B(2):86-99. 
[7] Vinod VC, Venkateswarlu M, Reddy GSP, et al. Pindborg tumor: review of literature and case reports. J Indian Acad Oral Med Radiol 2011;23(4):660-3.
[8] Kaplan I, Buchner A, Calderon S, et al. Radiological and clinical features of calcifying epithelial odontogenic tumour. Dentomaxillofac Radiol 2001;30(1):22-8. 